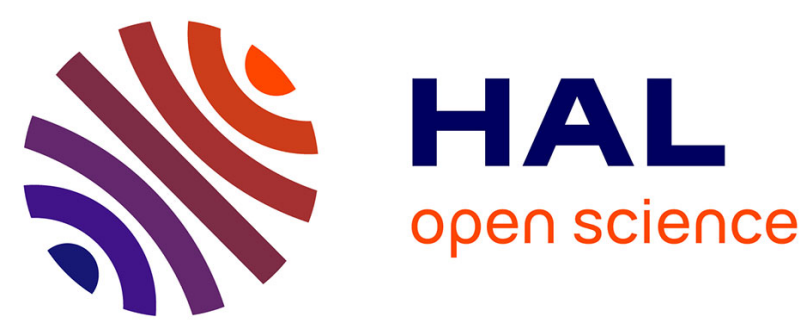

\title{
Colonic mesenchyme differentiates into smooth muscle before its colonization by vagal enteric neural crest-derived cells in the chick embryo
}

Annick Bourret, Norbert Chauvet, Pascal de Santa Barbara, Sandrine Faure

\section{- To cite this version:}

Annick Bourret, Norbert Chauvet, Pascal de Santa Barbara, Sandrine Faure. Colonic mesenchyme differentiates into smooth muscle before its colonization by vagal enteric neural crest-derived cells in the chick embryo. Cell and Tissue Research, 2017, 368 (3), pp.503 - 511. 10.1007/s00441-017-2577-0 . hal-01826912

\section{HAL Id: hal-01826912 \\ https://hal.umontpellier.fr/hal-01826912}

Submitted on 12 Dec 2019

HAL is a multi-disciplinary open access archive for the deposit and dissemination of scientific research documents, whether they are published or not. The documents may come from teaching and research institutions in France or abroad, or from public or private research centers.
L'archive ouverte pluridisciplinaire HAL, est destinée au dépôt et à la diffusion de documents scientifiques de niveau recherche, publiés ou non, émanant des établissements d'enseignement et de recherche français ou étrangers, des laboratoires publics ou privés. 


\title{
Colonic mesenchyme differentiates into smooth muscle before its colonization by vagal enteric neural crest-derived cells in the chick embryo
}

\author{
Annick Bourret $^{1} \cdot$ Norbert Chauvet $^{1} \cdot$ Pascal de Santa Barbara $^{1} \cdot$ Sandrine Faure $^{1,2}$
}

\begin{abstract}
During development, the gastrointestinal (GI) tract arises from a primary tube composed of mesoderm and endoderm. The mesoderm gives rise to the digestive mesenchyme, which in turn differentiates into multiple tissues, namely the submucosa, the interstitial cells of Cajal and the smooth muscle cells (SMCs). Concomitant with these early patterning events, the primitive GI tract is colonized by vagal enteric neural crestderived cells ( $\mathrm{vENCDCs}$ ), a population of cells that gives rise to the enteric nervous system, the intrinsic innervation of the GI tract. Reciprocal neuro-mesenchymal interactions are essential for the coordinated development of GI musculature. The aim of this study is to examine and compare the kinetics of mesenchymal cell differentiation into SMCs along the anterior-posterior axis to the pattern of vENCDCs migration using whole-mount in situ hybridization and paraffin section immunofluorescence analyses on chick embryonic GI tracts from E4-Stage 23 to E7Stages 30-31. We confirmed that gastric and pre-umbilical intestine mesenchyme differentiation into SMCs occurs after vENCDCs colonization. However, we found that colonic and post-umbilical intestine mesenchyme differentiation occurs before $\mathrm{vENCDCs}$ colonization. These findings suggest that
\end{abstract}

Sandrine Faure

sandrine.faure@inserm.fr

PhyMedExp, INSERM U1046, CNRS UMR 9214, University of Montpellier, 34295 Montpellier, France

INSERM U1046, Physiology and Experimental Medicine of Heart and Muscles, 371 Avenue du Doyen Giraud,

34295 Montpellier, France regional-specific mechanisms are involved in the mesenchyme differentiation into SMCs along the GI anterior-posterior axis.

Keywords Smooth muscle · Enteric nervous system · Colon · Stomach · Chick embryo

\section{Introduction}

The gastrointestinal (GI) tract is a vital organ essential for the absorption of water and nutrients. The GI tract is formed as a closed primitive tube from the association of the endoderm with the splanchnic mesenchyme at the early embryonic period. The primitive gut tube then becomes regionalized along the anterior-posterior (AP) axis into various organs such as the esophagus, stomach (proventriculus and gizzard in the chicken), duodenum and the intestines (small intestine and colon) and specialized along the radial axis into concentric layers of morphological and functionally distinct cell types (Roberts 2000). The endoderm gives rise to the mucosa lining the entire gut lumen and the mesenchyme differentiates mainly into circular and longitudinal smooth muscle layers that control gut contractions (de Santa Barbara et al. 2002). These processes of differentiation, according to different axes that are established during development, are essential for the digestive tract to ensure its basic function, namely food digestion, absorption of nutrients and water and elimination of feces (de Santa Barbara et al. 2002; Faure and de Santa Barbara 2011).

Smooth muscle cells (SMCs) have a mesoderm origin (Gabella 2002). The mesoderm gives rise to the digestive mesenchyme, which in turn differentiates into multiple tissues, such as the submucosa and the musculature, which is composed of SMCs and interstitial cells of Cajal (ICCs) (Wallace and Burns 
2005; Le Guen et al. 2015). Mesenchyme development into SMCs commonly occurs through two major steps (Gabella 2002). Mesenchymal progenitor cells first enter a determination program (which we will refer to as SMC determination), mainly characterized by the early expression of alpha smooth muscle actin ( $\alpha$ SMA) and SM22 (Faure et al. 2013; McKey et al. 2016). Later during development, determined SMCs enter a more differentiated state (which we will refer to as SMC differentiation), mainly characterized by the expression of proteins involved in smooth muscle contractility, such as CALPONIN and CALDESMON (McKey et al. 2016).

Concomitant with these early patterning events, the primitive GI tract is colonized by neural crest precursors, a population of cells that gives rise to the enteric nervous system (ENS), the intrinsic innervation of the GI tract. In chick, the ENS is predominantly derived from vagal enteric neural crestderived cells (vENCDCs) that migrate from the neural tube adjacent to somites 1-7 (Yntema and Hammond 1954; Le Douarin and Teillet 1973; Fairman et al. 1995; Burns and Le Douarin 1998; Burns et al. 2000). These cells exit the neural tube, enter the esophageal mesenchyme and begin an AP wave of migration through their interaction with mesenchymal extracellular matrix proteins (Burns and Le Douarin 1998; Breau et al. 2006). This allows vENCDCs to populate the entire GI tract, from the esophagus to the terminal colon. As the vENCDCs migrate along the GI tract, they proliferate and finally differentiate into neurons and glial cells of the ENS and form two concentric plexuses of ganglion cells localized in muscle layers of the GI wall (Heanue et al. 2016). In addition, sacral enteric neural crest cells (sENCCs), which originate from the caudal neural tube, first form the ganglion of Remak and then contribute to neurons and glia to the colorectum and post-umbilical intestine (Pomeranz and Gershon 1990; Burns and Le Douarin 1998).

While a number of studies have led to the identification of some of the molecular mechanisms that control differentiation of the mesenchyme into smooth muscle in the stomach (Sukegawa et al. 2000; Kim et al. 2005; Le Guen et al. 2009; Notarnicola et al. 2012; Jayewickreme and Shivdasani 2015; Sagnol et al. 2016; McKey et al. 2016), the examination of when mesenchyme differentiation occurs along the AP axis during GI development has not so far been reported. It has been suggested that GI mesenchyme differentiation into SMCs follows vENCDCs colonization. According to this, gut mesenchyme could mature in an AP direction (Fu et al. 2004; Wallace and Burns 2005; Olden et al. 2008). We examined the kinetics of mesenchyme differentiation and vENCDCs migration in detail using the chick embryo as a model. We previously reported that stomach mesenchyme determination is initiated after its colonization by vENCDCs (Faure et al. 2015). In this study, we focused on the posterior part of the gut. Our data show that the determination and differentiation of the mesenchyme in the post-umbilical intestine and colon is initiated before they are colonized by the vENCDCs.

\section{Materials and methods}

\section{Animals}

Timed fertilized white Leghorn eggs (Haas Farm, France) were incubated at $38{ }^{\circ} \mathrm{C}$ in a humidified incubator (Coudelou, France) until used experimentally. Embryos were staged according to Hamburger and Hamilton (1951) by embryonic day (E) for GI tract analysis. Dissected GI tissues were fixed in $4 \%$ paraformaldehyde for $1 \mathrm{~h}$ at room temperature, washed in PBS, gradually dehydrated in methanol in order to store the samples at $-20{ }^{\circ} \mathrm{C}$ before processing for whole-mount in situ hybridization as described below.

\section{Whole-mount in situ hybridization}

Whole-mount in situ hybridization analyses were carried out as described using antisense SOX10 (Moniot et al. 2004) and SM22 riboprobes (Faure et al. 2013). Tissues were gradually rehydrated in PBS, washed in PBT (PBS, $0.1 \%$ Tween) and incubated for $1 \mathrm{~h}$ in $6 \%$ hydrogen peroxide (Sigma, France). Samples were next permeabilized by treatment with proteinase $\mathrm{K}(10 \mu \mathrm{g} / \mathrm{ml})$ for $10 \mathrm{~min}$, washed with glycine in PBT and fixed in $4 \%$ paraformaldehyde $/ 0.2 \%$ gluteraldehyde in PBT for $20 \mathrm{~min}$. Tissues were then hybridized with antisense SOX10 or SM22 digoxigenin-labeled (Roche) riboprobes overnight at $70{ }^{\circ} \mathrm{C}$. After post-hybridization washes at $70{ }^{\circ} \mathrm{C}$, tissues were incubated in $10 \%$ sheep serum for $2.5 \mathrm{~h}$ at room temperature and finally mixed with preabsorded antidigoxigenin coupled with alkaline phosphatase antibody (Roche) overnight at $4{ }^{\circ} \mathrm{C}$. The complexes were detected with BM Purple, a chromogenic substrate for alkaline phosphatase (Roche).

\section{Immunofluorescence on paraffin sections}

For sectioning, tissues were first gradually dehydrated in ethanol, incubated in HistoClear solution (VWR, France) and finally embedded in paraffin. Samples were sectioned at $10 \mu \mathrm{m}$ using a microtome and collected on Polysine-coated slides (Thermo Fisher). Antigen retrieval was achieved by heating at $98{ }^{\circ} \mathrm{C}$ for $20 \mathrm{~min}$ in $1 \mathrm{mM}$ Tris- $\mathrm{HCl}(\mathrm{pH} 6.0$ ). Immunofluorescence studies were performed on paraffin sections using antibodies against $\alpha$ SMA (Sigma-Aldrich; dilution 1/400), CALPONIN (TEBU; clone CP19, dilution 1/200) and HNK-1 (NeoMarkers; dilution 1/200). Nuclei were labelled with Hoescht (Invitrogen, France). After washing, slides were incubated $30 \mathrm{~min}$ with Alexa 488 anti-mouse (Invitrogen; 1:2000 dilution) and Alexa 555 anti-rabbit (Invitrogen; 1:2000 dilution). Cells were rinsed again, mounted in Fluorescent Mouting Medium (Dako, France). Immunohistochemistry control experiments were performed by excluding the primary antibody (data not shown). 


\section{Photography}

Images were acquired using a Nikon Multizoom AZ100 stereomicroscope and a Carl Zeiss AxioImager microscope.

\section{Results}

\section{Determination of gut mesenchyme initiated in the chick embryo at $\mathrm{E} 4.5$ in post-umbilical intestine}

We first examined and compared the kinetics of vENCDCs migration and the differentiation of mesenchymal cells into SMCs by whole-mount in situ hybridization using SOX10 (marker of neural crest cells) and SM22 (marker of determined SMCs) probes on 4-day-old dissected GI tracts (E4 or Stage 23) (Fig. 1). At this stage, SOX10 expression is detected in the vENCDCs that have colonized the developing lungs and stomach (Fig. 1a, b). Posteriorly, SOX10 expression is observed in the sacral ENCCs (sENCCs) that form the ganglion of Remak
(R) (Fig. 1a, c). Conversely, SM22 transcripts were not detected at this stage in the whole GI tract (Fig. 1d-f). However, its expression is detected in the umbilical vessel (uv) associated with the intestine (Fig. 1d, f). Immunofluorescence analysis using both HNK-1 (marker of neural crest cells) and $\alpha$ SMA (marker of determined SMCs) antibodies indicated that at this stage, vENCDCs are randomly distributed in the mesenchyme of the developing stomach and duodenum (Fig. 1g, white arrowhead). No SMA-positive cells were detected in the GI tract (Fig. 1h), indicating that the mesenchyme had not yet began to be determined at this stage. However, we observed $\alpha$ SMApositive cells in the pharyngeal arches (pa) and in the allantois (al) (Fig. 1h).

At E4.5 (Stage 24), SM22 transcripts are not detected in the stomach mesenchyme (Fig. 2d, e). Interestingly, while the advancing wavefront of vENCDCs has reached the preumbilical intestine, as evidenced both by whole-mount in situ hybridization using $S O X 10$ probe (Fig. 2a, b) and immunofluorescence analysis using HNK-1 antibodies (Fig. 2g), a faint but detectable level of SM22 transcripts (Fig. 2f, arrowhead)
Fig. 1 vENCDC migration on the unspecified mesenchyme of chick GI tract at E4 (stage 23). Whole-mount in situ hybridization analysis of $S O X 10(\mathbf{a}-\mathbf{c})$ and SM22 expression (d-f) using antisense riboprobes. b, e Magnified views of the stomach. $\mathbf{c}, \mathbf{f}$ Magnified views of the colon. Migrating vENCDCs are localized in the lung and the stomach and the GI mesenchyme is undifferentiated at E4. Scale bars $1 \mathrm{~mm}$. Note $S M 22$ expression in the umbilical vessel found around the small intestine.

Immunofluorescence analyses performed on longitudinal paraffin sections using anti-HNK-1 (g) and anti- $\alpha$ SMA (h) antibodies. Scale bars $500 \mu \mathrm{m}$. al alantois; co colon; $l g$ lung; $R$ ganglion of Remak; pa pharyngeal arches; st stomach; $u v$ umbilical vessel; $v E N C D C s$ vagal enteric neural crest-derived cells
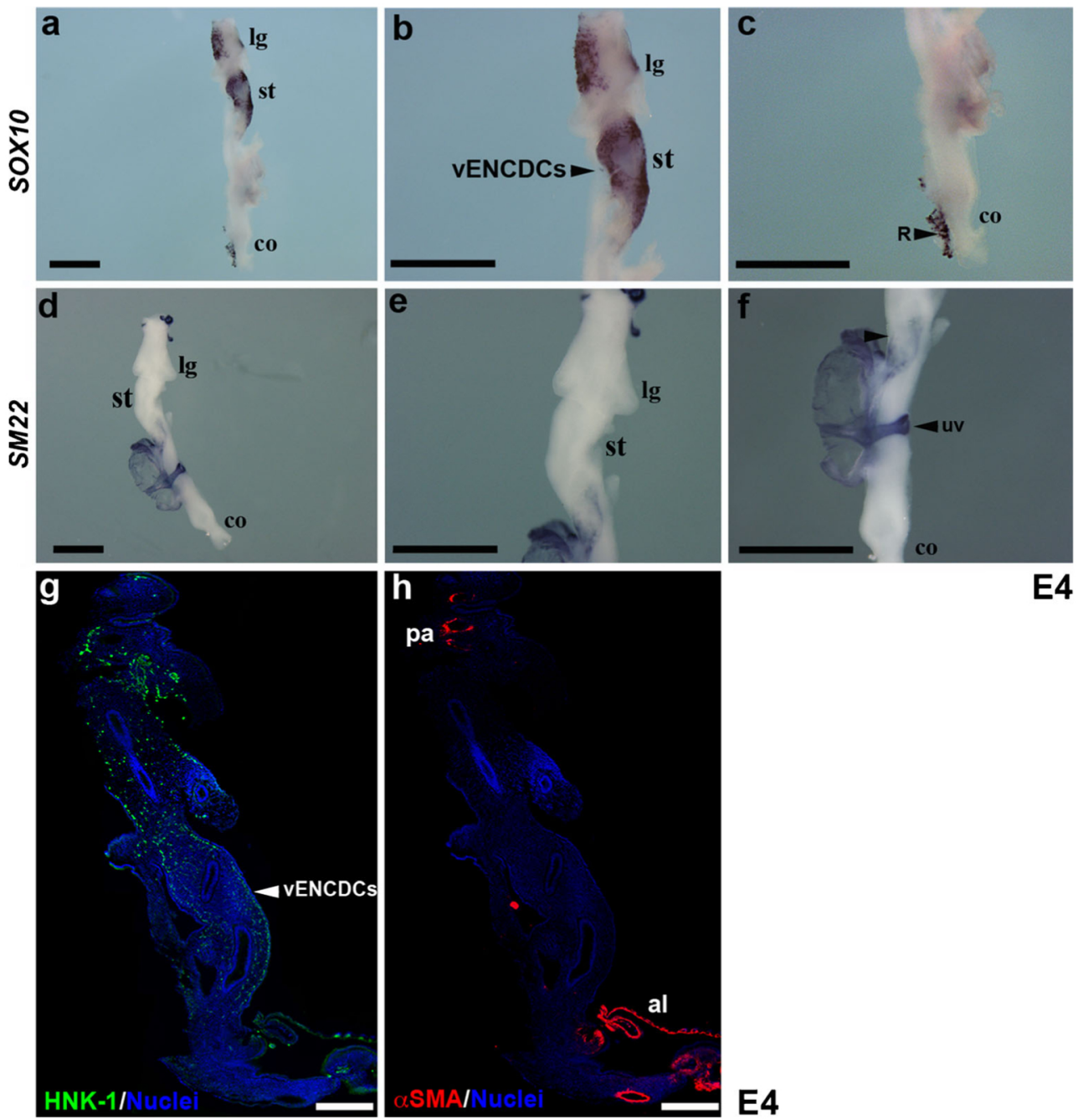

E4 
Fig. 2 Post-umbilical intestine mesenchyme determination is initiated at E4.5 (stage 24). Whole-mount in situ hybridization analysis of $S O X 10(\mathbf{a}-\mathbf{c})$ and SM22 expression (d-f) using antisense riboprobes. b, e Magnified views of the stomach. $\mathbf{c}, \mathbf{f}$ Magnified views of the colon. Mesenchyme determination is observed in the post-umbilical intestine area. Scale bars $1 \mathrm{~mm}$. Note SM22 expression in the umbilical vessel that is present around the small intestine. Immunofluorescence analyses performed on longitudinal paraffin sections using anti-HNK-1 (g) and anti- $\alpha$ SMA (h) antibodies showing, respectively, the presence of vENCDCs in the duodenum and sENCCs in the ganglion of Remak (R). Note the presence of determined mesenchymal cells in the post-umbilical intestine (white arrowheads). White arrow indicates the unspecific HNK-1 staining in the mesenchyme of the ceca (g). Scale bars $500 \mu \mathrm{m}$. co colon; $l g$ lung; $R$ ganglion of Remak; st stomach; $u v$ umbilical verssel; $v E N C D C s$ vagal enteric neural crest-derived cells
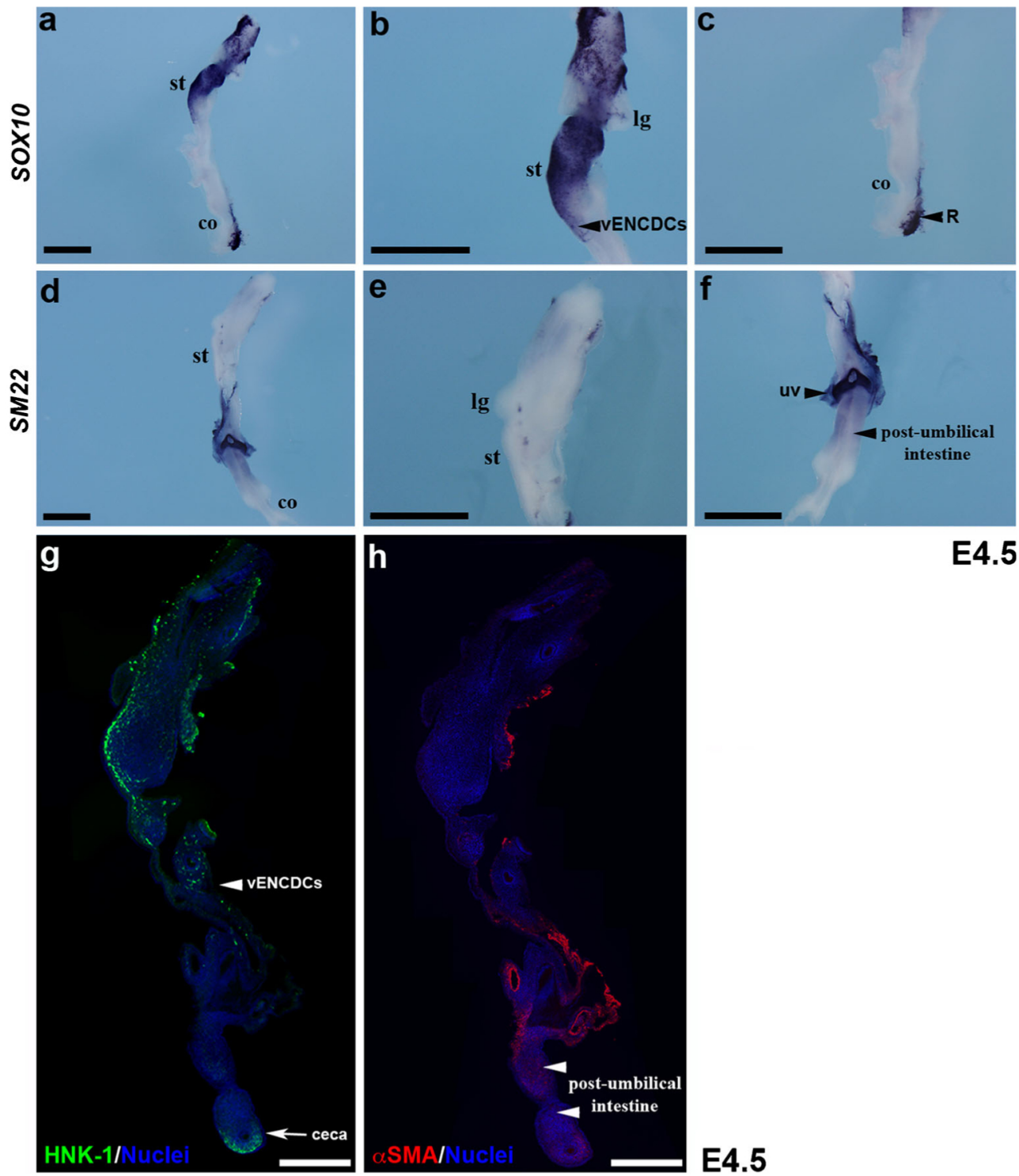

E4.5 and $\alpha$ SMA protein (Fig. 2h, white arrowheads) was detected in the post-umbilical intestine, indicating that mesenchyme determination was initiated at this level of the GI tract.

\section{Determination of stomach and colon mesenchyme observed in chick embryo at E5.5}

At E5.5 (Stage 27), SM22 transcripts were detectable both in the stomach (Fig. 3d, e) (Faure et al. 2015), the colon and the rectum (Fig. 3d, f), indicating that determination of stomach and colon mesenchyme occurs at similar stages in the chick embryo. SM22 expression was undetectable in the duodenum and the pylorus mesenchyme (Fig. 3d, e, white arrowhead). In the small intestine, SM22 expression is faint in the ileum (il) and strong in the jejunum (je) (Fig. 3d, e). Immunofluorescence analysis revealed $\alpha \mathrm{SMA}$ immunoreactivity in the colon and rectum at this stage (Fig. 3i-1, white arrowheads) while the advancing wavefront of vENCDCs only reached the post-umbilical intestine, as evidenced both by SOX10-whole-mount in situ hybridization analysis (Fig. 3a, c) and immunofluorescence analysis for HNK-1 (Fig. 3g, h, k, 1). This observation indicates that determination of the mesenchyme in the colon is initiated while the colon is not yet populated by the vENCDCs. Immunofluorescence analysis performed on adjacent section using CALPONIN antibodies (a marker of differentiation) did not reveal CALPONIN immunoreactivity in the GI tract at this stage, indicating that determined mesenchyme had not yet began to be differentiated (data not shown).

\section{Differentiation of stomach and colon mesenchyme observed in chick embryo at E6}

At E6 (Stage 29), SM22 is expressed in the entire GI tract (Fig. 4d-f) with the exception of the intermuscular tendon domain, found in the stomach and the pylorus (Fig. 4d, e, white 
Fig. 3 Colonic mesenchyme determination is initiated before vENCDCs colonization. Wholemount in situ hybridization analysis of $S O X 10(\mathbf{a}-\mathbf{c})$ and $S M 22$ expression (d-f) using anti-sense riboprobes was performed at E5.5 (stage 27). b, e Magnified views of the stomach. c, f Magnified views of the colon. Mesenchyme determination is observed in the colon and small intestine sparing the duodenum area (d, e, white arrowhead). At this stage, the migrating vENCDCs have reached the ileum but did not enter into the colon. Scale bars $1 \mathrm{~mm}$. Immunofluorescence analyses performed on longitudinal paraffin sections using antiHNK-1 (g, h, k, l) and anti$\alpha$ SMA (i-l) antibodies showing, respectively, the presence of vENCDCs in ileum but not in the colon structure, while determined mesenchymal cells are observed in the colon $(\mathbf{j}, \mathbf{l}$, white arrowheads). Note that, at this stage, HNK-1 staining was observed posteriorly in the ganglion of Remak ( $\mathbf{g}, \mathbf{h}, \mathbf{k}, \mathbf{l}$, white arrows). Scale bars $200 \mu \mathrm{m}$. Aco colon; il ileum; je jejunum; $R$ ganglion of Remak; st stomach; $v E N C D C s$ vagal enteric neural crest-derived cells
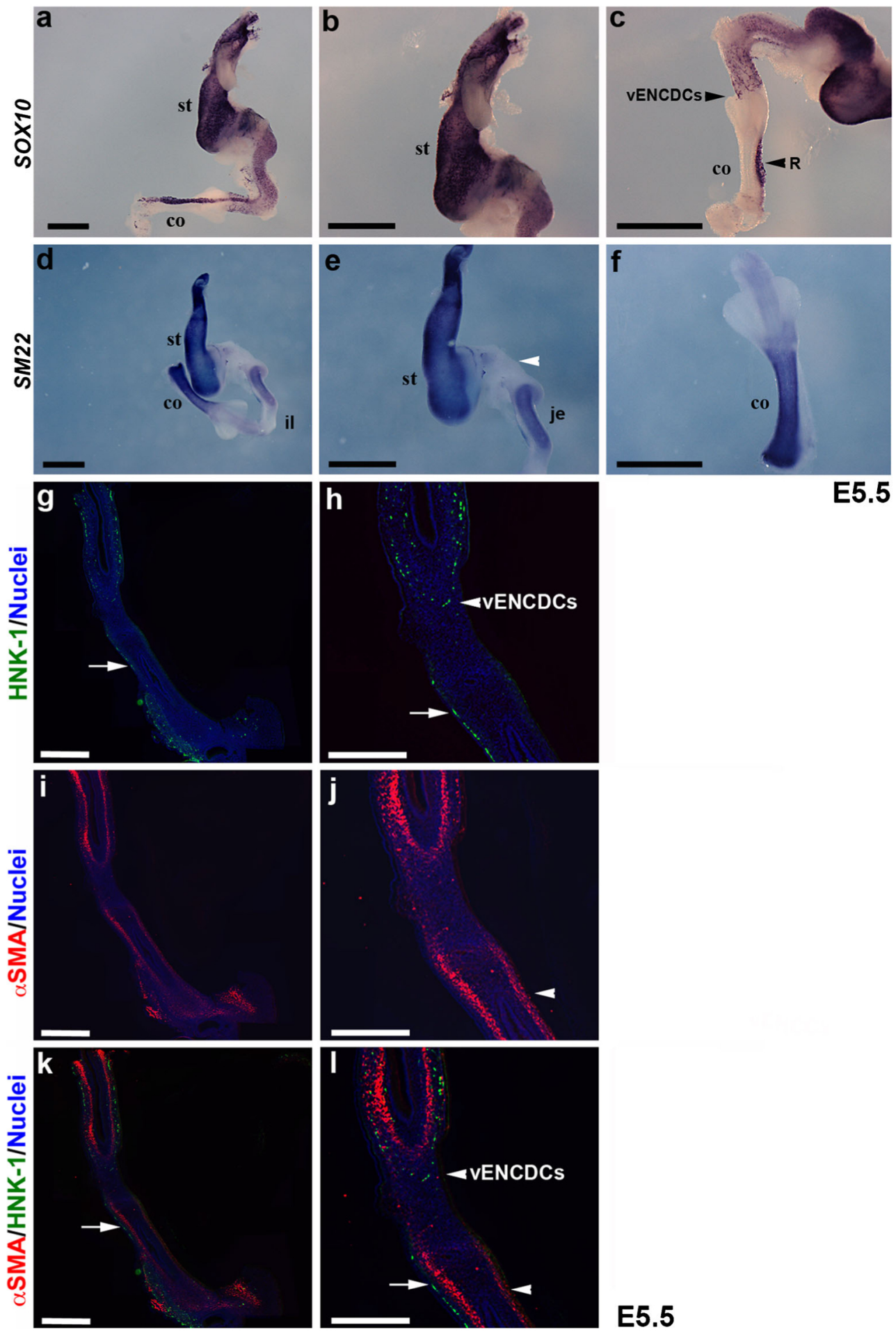

E5.5 arrowead), a posterior stomach structure while this domain is positive for SOX10 expression (Fig. 4b). Immunofluorescence analysis revealed a strong $\alpha$ SMA and CALPONIN expression both in the stomach (Fig. 4g, h) and the colon (Fig. 4i, j). At this stage, the colon is not populated by the vENCDCs as demonstrated by SOX10-whole-mount in situ hybridization analysis (Fig. 4a, c), showing the advancing wavefront of vENCCs at the level of the caecum and HNK-1 immunoreactivity (Fig. 4i, j, white arrowhead). Indeed, at E7 (Stages 30-31), while the rectum is not yet colonized by the vENCDCs, as shown both by whole-mount in situ hybridization and immunofluorescence analysis (Fig. 5a, c, g), it harbors a high level of expression of determined (SM22 and $\alpha$ SMA) and differentiated (CALPONIN) SMC markers (Fig. 5d, f, g, h). We observed that 
Fig. 4 Colonic mesenchyme differentiation is initiated before vENCDCs colonization. Wholemount in situ hybridization analysis of $S O X 10(\mathbf{a}-\mathbf{c})$ and $S M 22$ expression (d-f) using anti-sense riboprobes was performed at E6 (stage 29). b, e Magnified views of the stomach. c, f Magnified views of the colon.

Immunofluorescence analyses performed on longitudinal paraffin sections in the stomach $(\mathbf{g}, \mathbf{h})$ and the colon (i, j) using both anti- $\alpha$ SMA and anti-HNK-1 $(\mathbf{g}, \mathbf{i})$ or anti-CALPONIN antibodies (h, j) showing, respectively, the presence of vENCDCs in the ileum but not in the colon, while differentiated mesenchymal cells are found both in the stomach and colon. Note the expression of $\alpha$ SMA and CALPONIN in the blood vessel $(\mathbf{i}, \mathbf{j})$. Note that, at this stage, HNK-1 staining was observed posteriorly in the ganglion of Remak (i). Scale bars $200 \mu \mathrm{m}$. $b v$ blood vessel; $c a e$ caecum; co colon; il ileum; $R$ ganglion of Remak; st stomach; $v E N C D C s$ vagal enteric neural crest-derived cells
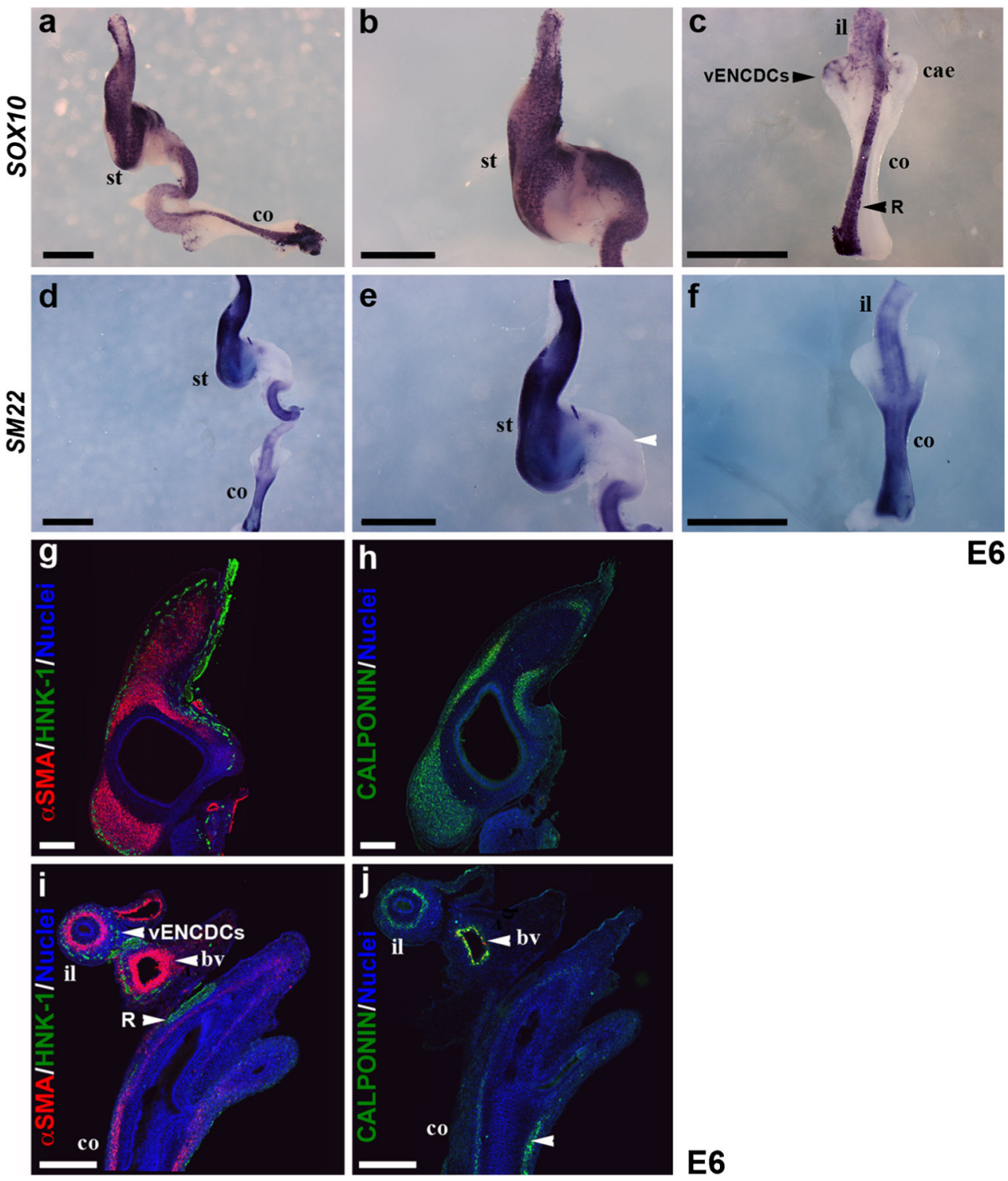

E6 the mesenchyme of the pylorus is still not determined at E7 (Stages 30-31) (Fig. 5e, white arrowhead). However, a faint level of SM22 staining in this structure was detected from E7.5 (Fig. S1).

\section{Discussion}

As they develop, each region of the GI tract acquires mesodermal and endodermal morphologies that can be easily discerned by gross and microscopic examination (Roberts 2000). These tissues differentiate in a regionally specific pattern along the AP axis, designating the stomach, small intestines (duodenum, jejunum and ileum) and large intestines (colon and rectum). In addition to this AP axis patterning, the digestive mesenchyme differentiates and gives rise to the submucosa and smooth muscle layers. Patterning along the AP axis has been extensively examined and the importance of epithelio-mesenchymal interactions well established (Roberts et al. 1998; Roberts 2000; de Santa Barbara and Roberts 2002). However, digestive mesenchymal differentiation of the gut is poorly studied, while alterations of GI musculature have been observed in different digestive motility disorders such as chronic intestinal pseudoobstruction syndrome (Antonucci et al. 2008; Boeckxstaens et al. 2002; Notarnicola et al. 2012; Chetaille et al. 2014). While recent studies have investigated some of the molecular mechanisms that control the differentiation of the mesenchyme of the stomach (for review, see Le Guen et al. 2015), the examination of when mesenchyme differentiation occurs along the AP axis in the developing GI tract has not so far been reported.

Here, we report that determination of GI mesenchyme is initiated in the chick embryo at E4.5 at the level of the postumbilical intestine. At E5.5, determination of mesenchyme 
Fig. 5 Differentiation of GI smooth muscle at E7. Wholemount in situ hybridization analysis of $S O X 10(\mathbf{a}-\mathbf{c})$ and $S M 22$ expression $(\mathbf{d}-\mathbf{f})$ was performed at E7 (Stages 30-31) using antisense riboprobes. b, e Magnified views of the stomach. $\mathbf{c}, \mathbf{f}$ Magnified views of the colon. Smooth muscle in the whole GI tract sparing the duodenum and pylorus areas (arrowhead in e). Migrating vENCDCs have reached the middle of the colon. Scale bars $1 \mathrm{~mm}$.

Immunofluorescence analyses performed on longitudinal paraffin sections on the colon using both anti- $\alpha$ SMA and anti-HNK-1 (g) or anti-CALPONIN (h) antibodies showing respectively the wavefront of vENCDCs migration at the level of the mid-colon while digestive SMCs are detected in the colon. Note that, at this stage, HNK-1 staining was observed posteriorly in the ganlion of Remak (g). Scale bars $200 \mu \mathrm{m}$ ap anal plate; co colon; $R$ ganglion of Remak; re rectum; st stomach; $v E N C D C s$ vagal enteric neural crest-derived cells
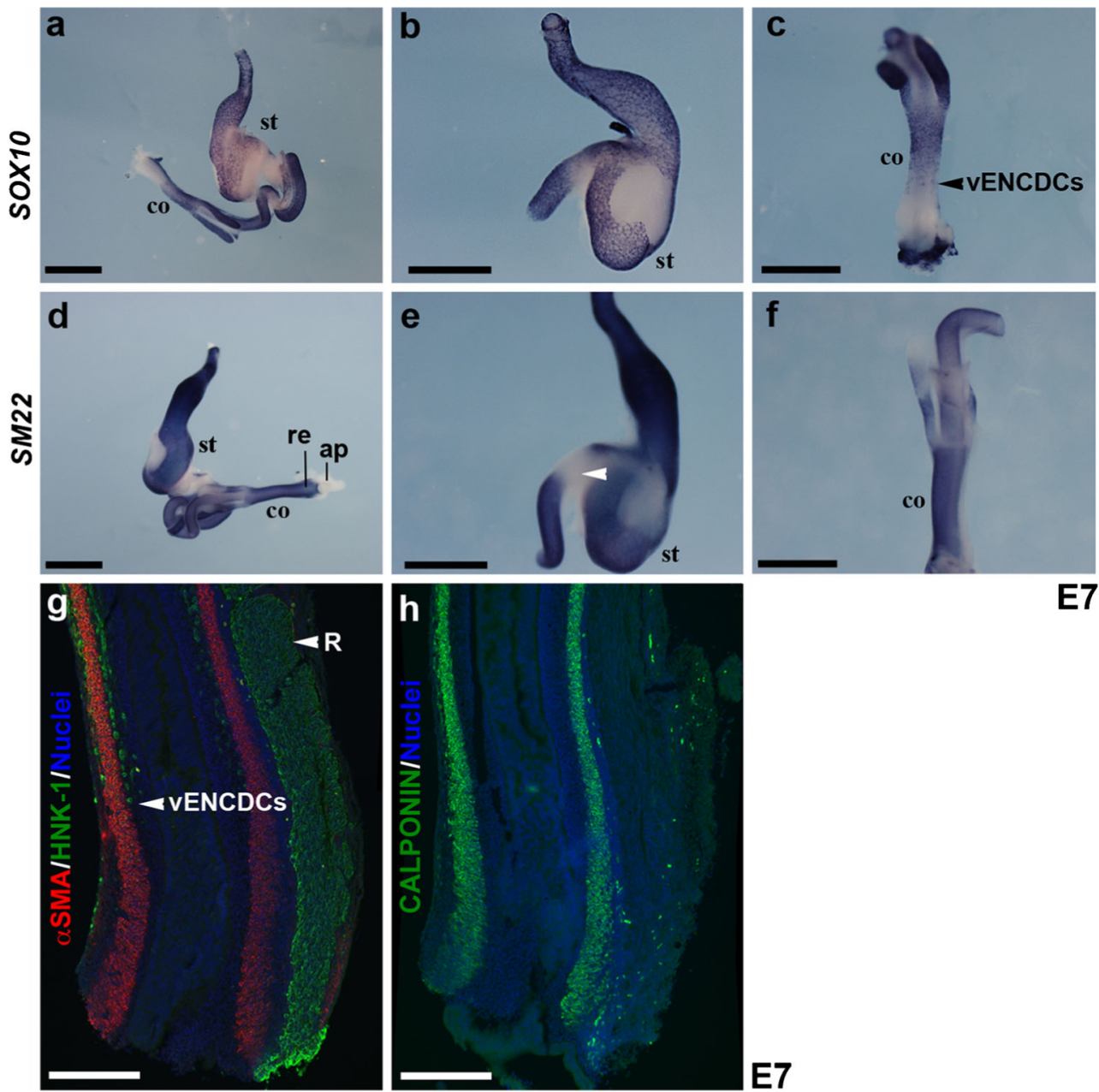

was observed in the stomach and colon. We observed that the mesenchyme of the pylorus, a structure that connects the stomach to the duodenum (Moniot et al. 2004) and the duodenum were still not determined at E7. All together, these observations show that mesenchymal cells of the GI tract do not follow a global AP wave of differentiation in the chick embryo. These findings suggest regional-specific intrinsic or extrinsic mechanisms of mesenchyme differentiation along the AP axis in the GI tract. Developing pylorus and duodenum are two particular GI structures that undergo remodeling at these stages in order to give rise, respectively, to the pyloric sphincter and the connection with the pancreas (Roberts 2000; de Santa Barbara et al. 2002; Grapin-Botton 2005). These tissular events could explain why mesenchyme differentiation is not initiated at these levels. Moreover, the specific expression of different members of the WNT signaling pathway (TCF4 and SOX9) observed in the pyloric mesenchyme at E7 (Moniot et al. 2004; Theodosiou and Tabin 2003) could regulate mechanisms that inhibit mesenchyme differentiation.

We also examined in detail the kinetics of mesenchyme differentiation and vENCDCs migration. Our data show that, in the pre-umbilical part of the GI tract, mesenchyme differentiation in SMCs occurs after the vENCDCs colonization (Faure et al. 2015; this study) and we previously showed that a critical number of vENCDCs is necessary for stomach mesenchyme differentiation (Faure et al. 2015). Interestingly, we report here that mesenchyme differentiation in SMCs in postumbilical intestine and colon starts in the absence of vENCDCs, suggesting that vENCDCs are not required for SMC differentiation in the post-umbilical part of the GI tract. During development, the post-umbilical mesenchyme, in addition to the vENCDCs, is also colonized by sENCCs that accumulated first in the ganglion of Remak of the mesorectum at E4.5 and then penetrate into the gut wall through dorsoventral migration at E7.5 (Pomeranz and Gershon 1990; Burns and Le Douarin 1998). Our data clearly show that mesenchyme differentiation in SMCs is initiated in the postumbilical intestine and colon well before penetration of the sENCCs into the mesenchyme. These observations suggest that $\mathrm{vENCDCs}$ are not required for SMC differentiation in the post-umbilical part of the GI tract, although we cannot rule out the influence of diffusible signals from sENCCs located in 
the ganglion of Remak that could participate in the determination of post-umbilical mesenchyme into SMCs. In addition, we observed that the umbilical vessel is associated with the developing intestine as soon as E4, close to the site of SMC determination in the post-umbilical intestine. Thus, it could influence the determination of the post-umbilical mesenchyme into SMCs.

When colonizing the stomach and the intestine, the migration front of vENCC is located in the outermost layer of the mesenchyme, adjacent to the serosal epithelium and will migrate inwards to set up plexuses (Tucker et al. 1984; Burns and Le Douarin 1998). In contrast, in the colorectum area, vENCDCs initially colonize the submucosal layer before migrating outwards to organize the myenteric plexus (Burns and Le Douarin 1998). Our data clearly show that, in the stomach, vENCDCs migrate through developing mesenchyme, while, in the colon, they migrate through differentiated smooth muscle. These results could in part explain the difference of colonization of vENCDCs into the colorectum compared to the other part of the GI tract. Moreover, it has been reported that interactions between vENCDCs and mesenchyme/muscle are critical for vENCDCs migration (Hao et al. 2016; Heanue et al. 2016). The digestive mesenchyme secretes neurotrophic factors whose receptors are located on the vENCDCs. Mesenchymal cells may express different repertoires of neurotrophic factors and extracellular matrix proteins depending on their status of differentiation (Hao et al. 2016; Breau et al. 2006; Raghavan and Bitar 2014). The status of mesenchyme differentiation could be critical for the development and migration of vENCDCs in the colon. In line with this hypothesis, we previously showed by using an avian-specific retroviral misexpression system that deregulation of BMP signaling within the mesenchyme of the colon impairs its differentiation into SMC and therefore induces abnormal vENCDCs development (de Santa Barbara et al. 2005). Our data point to the interest of further studies to identify specific pathways and factors that could be involved in the colonic SMC differentiation process.

Acknowledgements The author thanks the members of INSERM U1046.

Author contribution $\mathrm{AB}, \mathrm{NC}, \mathrm{PdSB}$ and $\mathrm{SF}$ performed experiments. $\mathrm{PdSB}, \mathrm{NC}$ and SF analysed results, contributed expertise and wrote the paper. PdSB and SF obtained funding.

\section{Compliance with ethical standards}

Funding Research was supported by a Trampolin grant $\left(\mathrm{N}^{\circ} 15681\right)$ from the Association Française contre les Myopathies (AFM) to SF and grants from AFM ( $\left.\mathrm{N}^{\circ} 18766\right)$, Fondation ARC and the French Association for CIPO patients to PdSB.

Conflict of interest No competing interests declared.

\section{References}

Antonucci A, Fronzoni L, Cogliandro L, Cogliandro RF, Caputo C, De Giorgio R, Pallotti F, Barbara G, Corinaldesi R, Stanghellini V (2008) Chronic intestinal pseudo-obstruction. World J Gastroenterol 14:2953-2961

Boeckxstaens GE, Rumessen JJ, de Wit L, Tytgat GN, Vanderwinden JM (2002) Abnormal distribution of the interstitial cells of cajal in an adult patient with pseudo-obstruction and megaduodenum. Am J Gastroenterol 97:2120-2126

Breau MA, Pietri T, Eder O, Blanche M, Brakebusch C, Fässler R, Thiery JP, Dufour S (2006) Lack of betal integrins in enteric neural crest cells leads to a Hirschsprung-like phenotype. Development 133: 1725-1734

Burns AJ, Le Douarin NM (1998) The sacral neural crest contributes neurons and glia to the post-umbilical gut: spatiotemporal analysis of the development of the enteric nervous system. Development 125:4335-4347

Burns AJ, Champeval D, Le Douarin NM (2000) Sacral neural crest cells colonise aganglionic hindgut in vivo but fail to compensate for lack of enteric ganglia. Dev Biol 219:30-43

Chetaille P, Preuss C, Burkhard S, Côté JM, Houde C, Castilloux J, Piché J, Gosset N, Leclerc S, Wünnemann F, Thibeault M, Gagnon C, Galli A, Tuck E, Hickson GR, El Amine N, Boufaied I, Lemyre E, de Santa Barbara P, Faure S, Jonzon A, Cameron M, Dietz HC, Gallo-McFarlane E, Benson DW, Moreau C, Labuda D, Canada Consortium FORGE, Zhan SH, Shen Y, Jomphe M, Jones SJ, Bakkers J, Andelfinger G (2014) Mutations in SGOL1 cause a novel cohesinopathy affecting heart and gut rhythm. Nat Genet 46:1245-1249

de Santa Barbara P, Roberts DJ (2002) Tail gut endoderm and gut/genitourinary/tail development: a new tissue-specific role for Hoxa13. Development 129:551-561

de Santa Barbara P, van den Brink GR, Roberts DJ (2002) Molecular etiology of gut malformations and diseases. Am J Med Genet 115: 221-230

de Santa Barbara P, Williams J, Goldstein AM, Doyle AM, Nielsen C, Winfield S, Faure S, Roberts DJ (2005) Bone morphogenetic protein signaling pathway plays multiple roles during gastrointestinal tract development. Dev Dyn 234:312-322

Fairman CL, Clagett-Dame M, Lennon VA, Epstein ML (1995) Appearance of neurons in the developing chick gut. Dev Dyn 204: 192-201

Faure S, de Santa Barbara P (2011) Molecular embryology of the foregut. J Pediatr Gastroenterol Nutr 52:S2-3

Faure S, Georges M, McKey J, Sagnol S, de Santa Barbara P (2013) Expression pattern of the homeotic gene Bapx1 during early chick gastrointestinal tract development. Gene Expr Patterns 13:287-292

Faure S, McKey J, Sagnol S, de Santa Barbara P (2015) Enteric neural crest cells regulate vertebrate stomach patterning and differentiation. Development 142:331-342

Fu M, Lui VC, Sham MH, Pachnis V, Tam PK (2004) Sonic hedgehog regulates the proliferation, differentiation, and migration of enteric neural crest cells in gut. J Cell Biol 166:673-684

Gabella G (2002) Development of visceral smooth muscle. Results Probl Cell Differ 38:1-37

Grapin-Botton A (2005) Antero-posterior patterning of the vertebrate digestive tract: 40 years after Nicole Le Douarin's PhD thesis. Int J Dev Biol 49:335-347

Hamburger V, Hamilton HL (1951) A series of normal stages in the development of the chick embryo. J Morph 88:49-92

Hao MM, Foong JP, Bornstein JC, Li ZL, Vanden Berghe P, Boesmans W (2016) Enteric nervous system assembly: functional integration within the developing gut. Dev Biol 417:168-181

Heanue TA, Shepherd IT, Burns AJ (2016) Enteric nervous system development in avian and zebrafish models. Dev Biol 417:129-138 
Jayewickreme CD, Shivdasani RA (2015) Control of stomach smooth muscle development and intestinal rotation by transcription factor BARX1. Dev Biol 405:21-32

Kim BM, Buchner G, Miletich I, Sharpe PT, Shivdasani RA (2005) The stomach mesenchymal transcription factor Barx1 specifies gastric epithelial identity through inhibition of transient Wnt signaling. Dev Cell 8:611-622

Le Douarin NM, Teillet MA (1973) The migration of neural crest cells to the wall of the digestive tract in avian embryo. J Embryol Exp Morphol 30:31-48

Le Guen L, Notarnicola C, de Santa Barbara P (2009) Intermuscular tendons are essential for the development of vertebrate stomach. Development 136:791-801

Le Guen L, Marchal S, Faure S, de Santa Barbara P (2015) Mesenchymal-epithelial interactions during digestive tract development and epithelial stem cell regeneration. Cell Mol Life Sci 72: 3883-3896

McKey J, Martire D, de Santa Barbara P, Faure S (2016) LIX1 regulates YAP1 activity and controls the proliferation and differentiation of stomach mesenchymal progenitors. BMC Biol 14:34

Moniot B, Biau S, Faure S, Nielsen CM, Berta P, Roberts DJ, de Santa Barbara P (2004) SOX9 specifies the pyloric sphincter epithelium through mesenchymal-epithelial signals. Development 131:37953804

Notarnicola C, Rouleau C, Le Guen L, Virsolvy A, Richard S, Faure S, De Santa Barbara P (2012) The RNA-binding protein RBPMS2 regulates development of gastrointestinal smooth muscle. Gastroenterology 143:687-697

Olden T, Akhtar T, Beckman SA, Wallace KN (2008) Differentiation of the zebrafish enteric nervous system and intestinal smooth muscle. Genesis 46:484-498
Pomeranz HD, Gershon MD (1990) Colonization of the avian hindgut by cells derived from the sacral neural crest. Dev Biol 137:378-394

Raghavan S, Bitar KN (2014) The influence of extracellular matrix composition on the differentiation of neuronal subtypes in tissue engineered innervated intestinal smooth muscle sheets. Biomaterials 35:7429-7440

Roberts DJ (2000) Molecular mechanisms of development of the gastrointestinal tract. Dev Dyn 219:109-120

Roberts DJ, Smith DM, Goff DJ, Tabin CJ (1998) Epithelialmesenchymal signaling during the regionalization of the chick gut. Development 125:2791-2801

Sagnol S, Marchal S, Yang Y, Allemand F, de Santa Barbara P (2016) Epithelial splicing regulatory protein 1 (ESRP1) is a new regulator of stomach smooth muscle development and plasticity. Dev Biol 414:207-218

Sukegawa A, Narita T, Kameda T, Saitoh K, Nohno T, Iba H, Yasugi S, Fukuda K (2000) The concentric structure of the developing gut is regulated by Sonic hedgehog derived from endodermal epithelium. Development 127:1971-1980

Theodosiou NA, Tabin CJ (2003) Wnt signaling during development of the gastrointestinal tract. Dev Biol 259:258-271

Tucker GC, Aoyama H, Lipinski M, Tursz T, Thiery JP (1984) Identical reactivity of monoclonal antibodies $\mathrm{HNK}-1$ and $\mathrm{NC}-1$ : conservation in vertebrates on cells derived from the neural primordium and on some leukocytes. Cell Differ 14:223-230

Wallace AS, Burns AJ (2005) Development of the enteric nervous system, smooth muscle and interstitial cells of Cajal in the human gastrointestinal tract. Cell Tissue Res 319:367-382

Yntema CL, Hammond WS (1954) The origin of intrinsic ganglia of trunk viscera from vagal neural crest in the chick embryos. $\mathbf{J}$ Comp Neurol 101:515-541 